\title{
Tailored surgery in elderly patients with breast cancer: our experience
}

\author{
S A Villari", F Famà, P Scarfò, A Pollicino, M A Gioffrè Florio \\ From de Senectute: Age and Health Forum \\ Catanzaro, Italy. 5-7 December 2009
}

\section{Background}

The incidence of breast cancer increases with advancing age. Although breast cancer in elderly patients presents corresponding biological characteristics to similar-stage cancer in younger women, the treatment is under standardized. This population is rarely included in randomized clinical trials. In absence of guide lines, tailored surgery has an important role in older women breast cancer treatment.

\section{Materials and methods}

From 2000 to 2008 we observed 162 cases of breast cancer in elderly women (65-88 years old).

Of these, $138(85,2 \%)$ were at a local stage, $24(14,8 \%)$ were locally advanced: $17(70,8 \%)$ stage IIIA, $5(20,8 \%)$ stage IIIB, $2(8,4 \%)$ stage IV. Comorbidity existed in $69 \%$ of cases.

Tailored surgery considers: clinical status of the patients, size, grade and location of the tumor. Were performed: 26 Madden modified mastectomy, 51 quadrantectomy, 47 segmentectomy, 38 lumpectomy. We prefer to carry out periareolar and sub-mammary incisions, it depends on the seat and stage of neoplasia.

\section{Results}

Our patients didn't have any complications after surgery and they have been satisfied with the aesthetical results. We have not observed local recurrences. Only two patients developed metastasis (1 cerebral and 1 pulmonary).

\section{Conclusions}

Tailored surgery represents good treatment for this population, because it evaluates clinical status, survival expectation, risk factors, comorbidity and respects the wishes of the patient who often prefers and asks for conservative surgery. Comorbidity seems to primarily influence the prognosis but not the immediate results. General anesthesia is performed for the treatment of the primitive tumor, axillary clearance and sentinel lymphonode dissection, otherwise, it is mandatory local anesthesia. In much older patients, residual breast radiotherapy depends onthe local recurrences risk and life expectation. Hormone therapy is recommended, because of the high receptorial positiveness, at this age. The scientific interest should be encouraged, because the extension of middle age, will inevitably involve an increased number of cases in elderly patients with these pathologies and will impose the identification of suitable therapeutic strategies. Today in our opinion, the best treatment must be tailored to the single patient.

Published: 19 May 2010

\section{References}

1. Sanguinetti A, Ragusa M, De Falco M, Sperlongano P, Calzolari F, Parmeggiani D, Misso C, Piatto A, Parmeggiani U, Avenia N: Locally advanced breast cancer in elderly patients: treatment standardised or tailored to individual needs? Chir Ital. 2007, 59(6):829-33.

2. De Cesare A, Burza A, Fiori E, Bononi M, Volpino P, Leone G, Crocetti A, Cangemi V: Assessment of surgical treatment in elderly patients with breast cancer. Tumori. 2008, 94(3):314-9.

doi:10.1186/1471-2318-10-S1-A38

Cite this article as: Villari et al:: Tailored surgery in elderly patients with breast cancer: our experience. BMC Geriatrics 2010 10(Suppl 1):A38.

Department of Emergency Care Unit, University of Messina, Italy 